\title{
Cycles and growth: an introduction
}

\author{
Sandra Steindl · Gunther Tichy
}

Published online: 16 September 2008

(C) Springer Science+Business Media, LLC. 2008

The interrelation between cycles and growth is still not fully understood by economic theory and even less so by economic policy. Growth theory tends to consider cycles as a bothersome, potentially overshooting adjustment resulting from disturbances ('shocks') to the growth path. Business cycle theory zooms in on deviations from the trend, ignoring potential interdependencies, and economic policy largely acts according to this very conception. This was not always so. For Schumpeter (1911, 1939), both business cycles as well as growth result from innovation. According to his conception, innovations occur almost necessarily in equilibrium, as this stage of the cycle implies zero profits for existing products and the stable environment facilitates risk assessment. Innovations and succeeding imitations trigger an expansion, which necessarily leads to a recession due to structural adjustment and a new higher equilibrium due to increased productivity. Most approaches after the World Economic Crisis as well implied either an inherent instability of growth (Harrod 1939; Domar 1946; Hicks 1950) or an inevitable emergence of disparities in the course of the growth process, resulting in a temporary crisis of structural adjustment (Mises 1928; Hayek 1933). In the sixties, recessions in the form of an absolute decline in economic activity ceased to occur. The growth cycle was invented, emphasising deviations from the trend, and implying different explanations of deviations and trends as well as separate policies. Business cycle theory emphasised sluggish adjustment at that time, due to rigid prices and wages or monetary disturbances (Friedman 1968); shocks were not considered important. Growth theory emphasized population growth and capital accumulation, with a subsequent emphasis on technical progress (Solow 1956).

\footnotetext{
S. Steindl $(\bowtie) \cdot$ G. Tichy

Austrian Institute of Economic Research, P. O. Box 90, 1103 Vienna, Austria

e-mail: sandra.steindl@wifo.ac.at

G. Tichy

e-mail: gtichy@oeaw.ac.at
} 
In the eighties, Nelson and Plosser (1982) started the debate on the nature of the dynamics of macroeconomic time series. Given the fact that after a shock the level of GDP does not show a significant trend-reversing tendency, the separation between growth and business cycle analysis was again put into question. Real Business Cycle (RBC) theorists (Kydland and Prescott 1982; Long et al. 1983) regarded an exogenous technological process as causing both output growth and business cycles. With the attempt to explain cyclical fluctuations in a neo-classical context, the dichotomy between growth and business cycle was broken. Although the model was mainly designed to explain or replicate cyclical fluctuations, it considers both features, economic growth and the business cycle, in a single model. In order to achieve the observed persistence in output dynamics, the technology shock was assumed to have a persistent nature, as the internal features of the basic model were not able to sufficiently propagate the shock (Cogley and Nason 1995). It was only with the inclusion of Keynesian features, such as rigidities (e.g. explicit modelling of price setting firms), monopolistic competition and variable capital utilization, that low persistent shocks were able to generate the observed persistence in output. Moreover, the basic RBC set-up was extended and became a point of departure for models in which not only technology shocks play a central role. While money behaves neutrally in the basic RBC model, starting with Cooley and Hansen (1989), money was seen thoroughly as a possible channel to affect the business cycle. Additionally, the standard RBC model was extended with demand shocks coming from the government or changing preferences.

Another way to model persistence is by incorporating elements of endogenous growth theory as a channel between the short- and long-run (Stadler 1990). Moreover, this yields the possibility of explaining trend output in a causal relationship with cyclical fluctuations. In theory, there are two contrasting ideas allowing business cycles to interact with long-term economic growth. In one approach, (small) recessions are considered to have a positive impact on growth by reducing opportunity costs (e.g. Hall 1991), while in the other, where growth takes the form of learning by doing and productivity enhancement is pro-cyclical, recessions (and in most cases volatility) have a negative effect on long-term growth (e.g. Stadler 1990). Starting with the contribution by Ramey and Ramey (1995), the sign of the relationship between growth and volatility has also been thoroughly investigated on empirical grounds. Of course, the outcome is of great interest for economic policy; depending on the kind of relationship, stabilization policy may be growth-stimulating or not. So far, however, a consensus on the sign of the relationship between growth and cyclical fluctuations has been found neither on theoretical nor on empirical grounds.

Nowadays, New-Keynesian Dynamic Stochastic General Equilibrium (DSGE) models are in principle able to explain most of the stylised facts of cycles, at least on average. ${ }^{1}$ The degree to which these models are appropriate for policy advice is less clear, however. An abundance of different models exist (some using elements of endogenous growth, others not), offering different explanations, with a limited chance to differentiate among them. Some of them imply growth-enhancing effects

\footnotetext{
1 As a consequence of calibration the models cannot follow the course of the individual cycles.
} 
of stabilisation policy, while others suggest attenuating ones. Most of the growth models do not deal with periods of subdued growth, as experienced by the US in the eighties or by Europe in the nineties. The models generally assume agents with perfect foresight, dynamically optimising their utility, an absence of involuntary unemployment, or consumption smoothing over the life cycle. Uncertainty is absent in these models, but policy cannot abstract from uncertainty, which is only too evident in surveys as well as in the economic press.

In line with its mandate to base its business cycle analysis and forecasts as well as its policy proposals on most recent theory, the Austrian Institute of Economic Research organised a conference on "The interrelation of cycles and growth" in September 2007 in Vienna. This volume comprises four of the most interesting papers.

We start with the paper by Comin, highlighting the interrelation of high and medium-term components, where the author defines the medium-term component as including frequencies between 32 and 200 quarters. The paper offers evidence of the connection between the two components by showing that, on the one hand, forces usually identified as driving high frequency fluctuations (such as total mark-up and capacity utilization) have a significant medium-term component, and, on the other hand, R\&D-which is assumed to drive medium-term fluctuations-was found to be variable at high frequency and correlated with output at high frequency. Given this evidence of a joint determination of fluctuations in both frequencies, the author incorporates elements of endogenous growth as a propagation mechanism in the model. To be more precise, persistence is modelled using pro-cyclical R\&D expenditures and the pro-cyclical speed of diffusion of technologies. Via these channels, a negative high-frequency shock leads to a reduction in the technologies adopted, which in turn affects productivity and eventually has a negative effect on aggregate output in the medium term. Therefore, like in Comin and Gertler (2006), the model is not only able to explain business cycles like New-Keynesian DSGE models with exogenous growth, but also cycles covering the medium term.

In line with Comin, Url et al. propose a model which includes the dynamics of both the short and the long term, but in their model long-term technology is exogenous and determined by the interaction with the rest of the world. Based on long-term restrictions derived from an open economy model, the authors design a quarterly co-integrating vector autoregression (VAR) model for the euro zone and the US, which enables them to quantify how a shock in one economy (e.g. in terms of GDP, interest rate or exchange rate) affects the cyclical stance of the other economy. Persistence arises in both economies due to the co-integrating relations capturing international spill-over, interest rates and exchange rate fluctuations. After the shock has affected both economies, an adjustment process starts where shortterm dynamics are data-driven, and eventually, in the long run, a new steady-state level of GDP is achieved.

In the model introduced by Barrell et al., where equilibrium output is determined by a production function, the link between short- and long-term economic behaviour is established using fixed capital formation as a channel. On the one hand, fixed capital formation causes cyclical fluctuations, while on the other hand, it also determines the long-term growth path. Investment demand is modelled as dependent 
on risk-adjusted user costs, with the main focus of the model on real exchange rate volatility. The latter is considered as proxy for risk affecting the risk-adjusted user cost of capital, and therefore determines the capital stock and, consequently, output in the long run. Additionally, output volatility itself increases the spread between risk free and corporate bonds, which again affects the risk-adjusted user costs of capital and eventually output in the long run. Using these channels, the reaction of long-term to short-term fluctuations is examined for a panel of European countries.

Similarly, Falk and Sinabell empirically investigate the relationship between short-term fluctuations and long-term economic growth. The authors use a sample of 1,084 European regions and a spatial econometric approach, assuming no specific link between economic growth and the business cycle. The paper contributes to the empirical literature by examining the cross-country heterogeneity in the link between growth and volatility. In addition, like in Imbs (2007), the authors show that the result depends on the aggregation level; at the aggregate cross-country level, the relationship is negative and of low significance, while on the disaggregated (in this case the regional) level the authors find the opposite. Apart from regions located in three countries, the authors find a positive relationship between growth and volatility.

Using different features as propagation mechanisms, the models in this volume are able to replicate-and/or show through their empirical results-the usual observed persistence in macroeconomic variables. Finding persistent level effects resulting from short-term economic shocks seems to confirm the existence of an interrelation between short-term and long-term dynamics. Considering the sign of the relationship, it is not surprising that the different models arrive at different results. Models using pro-cyclical productivity enhancement as propagation mechanism, such as in Comin, usually predict a negative relationship between long-term growth and economic volatility (Stadler 1990; Blackburn and Galindev 2003). A negative relationship between volatility and equilibrium output is also found in the model by Barrell et al. while the outcome given in Falk and Sinabell is less clear. The panel econometric results by Barrell et al. suggest that both, a reduction in the volatility of the exchange rate and in the volatility of output itself, increase the level of equilibrium output in the long run. While, in the spatial model by Falk and Sinabell the sign of the relationship between GDP growth and its volatility is on average found to be positive, though the relation is not uniform across countries. Moreover, for certain regions the results indicate a negative relationship between average economic growth and its standard deviation. The contribution by Url et al. does not trace the cyclical effects on long-term growth at all, as the growth path is determined exogenously and therefore unaffected by any kind of short-term shock. Given a shock to output in one country, both the euro zone and the US increase their levels of GDP permanently, but their growth rates are shifted temporarily.

If short-term dynamics affect the equilibrium level and the adjustment takes up to 5 years, as the papers by Barrell et al., Comin and Url et al. suggest, what does this imply for policy? Can policy reduce volatility and thereby raise growth rates until the higher equilibrium level is attained? Or can it speed up the adjustment process? Can policy prevent negative shocks by lowering the equilibrium level? The results by Falk and Sinabell give rise to doubts about the power of policy, as they cannot 
identify significant growth-enhancing effects of reduced volatility. Quite to the contrary: they emphasize a significant positive association at the regional level, as Imbs (2007) does for sectors. However, this does not automatically rule out policy effects: at the disaggregated level of regions, the volatility of individual dynamic branches may dominate, but these effects disappear at the aggregate level, partly due to compensation effects of a more balanced sectoral distribution, ${ }^{2}$ partly due to policy. Furthermore, Falk and Sinabell restrict their investigation to the decade 1995 to 2004 , a period of low volatility (cf. Barrell et al., this volume), rare shocks (Blanchard and Simon 2001) and a policy of restraint.

Several authors (e.g. Kneller and Young 2001; Byrne and Davis 2005) emphasize that the reduced output volatility of the most recent past results from less volatility of inflation, interest and exchange rates. The more stable environment has reduced risk and uncertainty and promoted capital formation and innovation. This line of reasoning is explicitly modelled in Barrell et al.: less volatile exchange rates reduce risk premiums and user costs of capital. The estimates by Url et al., even though they result from a very different model, do not contradict that, as the amplitude of PPP deviations, largely accounted for by exchange rate deviations, is about ten times that of interest rate and output-gap deviations, which turns exchange rates into an important driver; due to the character of the model, the mechanism is not explicitly modelled. Uncertainty evidently also prevails in Comin's equations, where pro-cyclical R\&D expenditures and the pro-cyclical speed of diffusion of technologies produce short and medium-term fluctuations. The model reproduces most stylised facts rather well, but the relative price of capital appears as too sticky and R\&D as too volatile. Entrepreneurs probably underestimate the expectation value of innovations in recessions and overestimate it in booms-a result of a cyclically varying level of uncertainty.

If varying levels of uncertainty are among the important drivers of business cycles and consequently of varying equilibrium levels of economic activity, business cycle policy has to reach far beyond the traditional instruments of monetary and fiscal policy. Removing institutions that induce instabilities which are hard to overcome by policy and supporting institutions that reduce the frequency of shocks, trim down their propagation effects or make the economy more shock resistant, becomes much more important.

Given the fact that about half of all past shocks originated from fiscal or monetary policy (Blanchard and Watson 1986), the reduction of shocks is a task of policy itself. The creation of the European Monetary Union and the resulting avoidance of opposing national policies was one important step towards this goal. Fiscal policies with a longer horizon and institutional adjustments to strengthen automatic stabilisers are possible further steps. While traditional stabilization policy attempted to stabilise one goal-mostly output or employment-by destabilising the other one that is used as an instrument, recent policy rather tries to avoid erratic changes and takes care to achieve a smoothing effect over a longer horizon.

\footnotetext{
$\overline{2}$ Acemoglu and Zilibotti (1997) show a strong relationship between income and volatility: richer countries are less volatile due to their more balanced sectoral distribution.
} 
Even more important are institutional arrangements to increase the economy's shock resistance. Efficient competition policy and a productivity-oriented wage policy aimed at avoiding excessive uncertainty-creating developments are examples of such arrangements, as are institutions fostering the crisis resistance of firms and workers, such as minimum capital requirements, insolvency legislation, or social networks serving to quickly integrate the temporarily unemployed in order to avoid hysteresis and persistence effects.

\section{References}

Acemoglu D, Zilibotti F (1997) Was Prometheus unbound by chance? Risk, diversification and growth. J Political Econ 91:938-963

Blackburn K, Galindev R (2003) Growth, volatility and learning. Econ Lett 79(3):417-421

Blanchard O, Simon J (2001) The long and large decline in US output volatility. Brookings Papers Econ Act 1:135-174

Blanchard OW, Watson MW (1986) Are business cycles all alike. In Gordon R (Ed) The American business cycle: continuity and change. pp 123-179

Byrne JP, Davis EP (2005) Investment and uncertainty in the G7. Rev World Econ 41(1):1-32

Comin D, Gertler M (2006) Medium-term business cycle. Am Econ Rev 96(3):523-551

Cogley T, Nason JM (1995) Output dynamics in real-business-cycle models. Am Econ Rev 85(3):492_ 511

Cooley TF, Hansen GD (1989) The inflation tax in a real business cycle model. Am Econ Rev 79(4):733748

Domar E (1946) Capital expansion, rate of growth and employment. Econometrica 14(2):137-147

Friedman M (1968) The role of monetary policy: presidential address to AEA. AER 58(1):1-17

Hall RE (1991) Recessions as reorganizations, NBER Macroeconomic Annual 1991

Harrod R (1939) An essay in dynamic theory. Econ J 49:14-33

Hayek FA (1933) Geldtheorie und Konjunkturtheorie. Hölder-Picher-Tempsky, Wien, Leipzig

Hicks JR (1950) A contribution to the theory of the trade cycle. Clarendon, Oxford

Imbs J (2007) Growth and volatility. J Monet Econ 54:1848-1862

Kneller R, Young G (2001) Business cycle volatility, uncertainty and long-run growth. Manchester School 6(5):534-552

Kydland FE, Prescott EC (1982) Time to build and aggregate fluctuations. Econometrica 50(6):13451370

Long JB, Plosser ChI (1983) Real business cycles. J Political Econ 91(11):39-69

Mises L (1928) Geldwertstabilität und Konjunkturpolitik, Jena

Nelson CR, Plosser CI (1982) Trends and random walks in macroeconomic time series: some evidence and implications. J Monet Econ 10:139-162

Ramey G, Ramey VA (1995) Cross-country evidence on the link between volatility and growth. Am Econ Rev 85(5):1365-1379

Schumpeter JA (1911) Theorie der wirtschaftlichen Entwicklung. Duncker \& Humolt, Berlin

Schumpeter JA (1939) Business cycles: a theoretical, historical, and statistical analysis of the capitalist process. McGraw Hill, New York, London

Solow RM (1956) A contribution to the theory of economic growth. Q J Econ 70:65-94

Stadler G (1990) Business cycle models with endogenous technology. Am Econ Rev 80(2):763-778 